\title{
EXPLORING THE TEACHING EXPERIENCES OF TEACHERS USING COMPUTER-BASED ASSESSMENTS WHEN TEACHING INTERACTIVE MULTIMEDIA CLASSES
}

\author{
Nafeth Al Hashlamoun and Lina Daouk \\ Computer and Information Science Department, Higher Colleges of Technology, Abu Dhabi, UAE
}

\begin{abstract}
This research explores the experiences of using Computer-based Assessments (CBA) in teaching an introductory level class called Introduction to multimedia (CIS 1503). This course is the first multimedia course in the Computer and Information Systems (CIS) department that is running at a Higher Education Institute in the Middle East (HEIME). It introduces students to various multimedia components such as $2 \mathrm{D}$ graphics, audio and video. The core objective of this course is to provide students with practical experience in various stages involved in the design, development and delivery of interactive multimedia content.

A phenomenological approach has been chosen to help understand and explore the participants' awareness of the phenomenon under investigation and that is "Using CBA in teaching interactive multimedia classes". Three specific questions were considered. These questions were investigated from the teachers' point of view.

The data explicitation process (as defined and used by (Giorgi, 2009)) resulted in forming four central themes representing the essence of the original ones. The central themes were: (1) to manage the teachers' marking load; (2) to enhance student satisfaction and attentiveness; (3) to support the management of assessments; and (4) to provide an effective archiving system for assessments and students' work. This was followed by a discussion of the opportunities and challenges arising from using CBAs in teaching this particular course. A description of the limitations within this research was also listed at the end of the study.
\end{abstract}

\section{KEYWORDS}

Computer-Based Assessments, Phenomenology, Assessments, Phenomenological Research

\section{INTRODUCTION}

The fast evolution of Information and Communication Technology (ICT) in the field of teaching and learning opened up new possibilities for delivering learning contents and examination. This has encouraged educational institutions to change from paper-based to computer-based assessments (Clariana and Wallace, 2002; Deutsch et al., 2012). In agreement with this and in accordance with their strategic planning, the HEIME has reviewed all its programmes with the aim of providing a learning environment of the highest standards. This was done by incorporating the latest teaching methodologies and learning technologies. In turn, teachers were encouraged to use proper technologies in order to meet the new challenges of designing and implementing assessment methods that go beyond the conventional practices.

Consequently, teachers teaching the CIS 1503 course shifted from using paper-based to computer-based assessments. The online tool that the CIS 1503 teachers used for their assessments was a Blackboard Learn tool called 'Tests and Surveys'. This tool was used to measure student knowledge, gauge their progress, and gather information from them.). 


\section{THEORETICAL FRAMEWORK}

The theoretical framework used in this study is phenomenology, a theoretical framework that focuses on exploring how human beings make sense of their experiences and transfer these experiences into consciousness, both in isolation and as shared meaning (Patton, 2002). Phenomenology aims to clarify the structure and meaning of a phenomenon via the person's description. It is used to determine thorough descriptions of participants' experiences. These descriptions are used to conduct a "structural analysis which portrays the general meaning or essence of experiences" (Moustaka, 1994, p. 13).

\section{METHODOLOGY}

As defined by Maypole and Davies (2001), a phenomenological research is a descriptive method that tries to understand the lived experiences of the people who were involved with the issue that is being researched. The phenomenological approach must be clearly distinguished from the phenomenographic approach. They are related in that each is based on the term "phenomenon", which means "to bring to light". However, although phenomenography and phenomenology have much in common, they have different aims, methods and goals, and therefore different results. Phenomenography refers to a research approach aiming at describing the different ways a group of people understand a phenomenon (Larsson and Holmström, 2007). Likewise, it aims to document the range and variety of experiences informants bring to the topic of interest, whereas phenomenological approach aims to clarify the structure and meaning of a phenomenon. Following the same line of thought, a phenomenological study captures what the German philosopher, Husserl (1931) referred to as the "essential character" of the experience through the eyes of the participants (who are the "teachers" in this study). Hence, Phenomenology is an appropriate research method to discover what Husserl would call the teachers' lived experiences.

This study followed a phenomenological approach, with the aim of answering three different research questions. The first was about the range of teachers' experiences in using online CBA in teaching Interactive Multimedia classes; the second was about the values derived from using online CBA in teaching this particular course, and the third was about the changes that teachers have seen in students' day-to-day practices.

The phenomenological interviews were designed to bring forth the interviewees' awareness of the phenomenon under investigation (Marton \& Booth, 1997, Moustaka, 1994, Prosser et al., 1994). Interviewees were provided with information about the aim of the study prior to participating in the interviews. Interviews lasted 40 to 50 minutes each. At the beginning of each interview, interviewees were asked 'seed' questions related to their previous experiences and the number of times they had used computer-based assessments while teaching the CIS 1503 course. Interviewees started by talking about their experiences in terms of the phenomenon under study (which is using CBAs in teaching this course). This semester, three CIS teachers are teaching the Interactive Multimedia course in Khalifa City campus, which is one of seventeen campuses that make up the HEIME. All of these teachers were asked to participate in the study. They all had taught the course before without using any computer-based assessment tool. The characteristics of the interviewees are presented in Table 1 below.

Table 1. Demographics of the Interviewees

\begin{tabular}{|c|c|c|c|}
\hline & Teaching Experience & $\begin{array}{c}\text { Number of times teaching the } \\
\text { course without using } \\
\text { computer-based assessments }\end{array}$ & $\begin{array}{c}\text { Number of times teaching the course } \\
\text { using computer-based assessments } \\
\text { (including this semester) }\end{array}$ \\
\hline Interviewee-1 & 9 years & 4 times & 2 time \\
\hline Interviewee-2 & 17 years & 1 time & 1 time \\
\hline Interviewee-3 & 10 years & 3 times & 2 times \\
\hline
\end{tabular}




\section{THE EXPLICITATION OF THE DATA}

According to Hycner (1985), an explicitation of data versus an analysis is necessary in a phenomenological research. The reason being that the word analysis implies breaking something into parts and consequently a loss of the whole phenomena, while explicitation looks at all the constituents of the phenomena, keeping the whole in context. In view of that, five explicitation steps were applied

\subsection{Bracketing and Phenomenological Reduction}

As stated by Gearing (2004), bracketing is a "scientific process in which a researcher suspends or holds in abeyance his or her presuppositions, biases, assumptions, theories, or previous experiences to see and describe the phenomenon". Similarly, Tufford and Newman (2012) define bracketing as a method used to mitigate the potential negative effects of the researcher's presumptions that are related to the study, and as a result, increase the rigor of the project. Moustaka (1994) has also suggested that the researcher should not make any presumptions and concentrate on a particular issue "freshly and naively". These recommendations were used to avoid improper subjective judgment and to allow the phenomena to emerge fully and holistically from the interviews. For instance, the researchers started the analysis of data by specifying what they thought they might find (such as: "both teachers and students believe that computer-based assessments are very good"). Then they put these expectations aside in order to hear what emerges from the data. This helped the researchers to extract the "pure" phenomena from the participants' viewpoint.

\subsection{Listening to the Interview Recordings Repeatedly}

As advised by Hycner (1985) and Creswell (2012, p. 273), the interviews in this research were listened to repeatedly to allow the researchers to develop a holistic sense of the phenomenon. Besides, Creswell (2012) stated that there is a need to read through the data in order to obtain an overall sense of the material. Hence, the transcripts were examined thoroughly more than once. Special attention was given to the non-verbal and para-linguistic levels of communication. For instance, two of the interviewees kept changing their voice levels and pitch along with the changes in the topics of discussions. One of them spoke softly and slowly when she was hesitant to discuss a sensitive issue. Oppositely, the other interviewee used an increased volume when she was happy about some issues.

\subsection{Delineating the Codes (Units of Meaning)}

At this stage, the researchers started to investigate the data carefully. They tried to make sense out of the text data by picking up the essence of the meaning expressed in words, phrases, sentences, paragraphs, and non-verbal or para-linguistic cues during the interview (Hycner, 1985). Further to that and based on Creswell's recommendation, the entire transcript was coded. "Coding is the process of segmenting and labelling text to form descriptions and broad themes in the data" (Creswell, 2012, p. 243). Hence, the interview data was analyzed for noteworthy statements, sayings, or quotes that help the researchers comprehend how the participants experienced the phenomenon. A list of codes (units of relevant meaning) was created, and redundant ones were recognized. This resulted in a smaller and more manageable number of codes. These codes are shown in the left column of Table 2.

\subsection{Clustering of Codes (the Units of Relevant Meaning) to Form Themes}

At this stage of the process, similar codes were clustered together to form the themes. To achieve that, the researchers tried to identify and group the codes that seem to "fit together" to describe a major idea. For example, as is illustrated in the second row in Table 2, the following codes: "Marking essays can't be automatic", "Marking the essay questions is an issue", "Not easy", and "Takes the same time" seem to fit together to describe the major idea "Difficulty in marking essay questions". 
Upon the analysis of the themes that appear in the second column of Table 2, clusters of themes were gathered together creating what Hycner (1985) terms as "central themes" that express the essence of these themes. The clusters, the themes, and the developed central themes are presented in Figure 1. In this figure, the dark boxes at the top of the diagram contain the central themes, the bolded headings at the top of each white box represent the themes, and the points listed in the white boxes represent the codes (unites of relevant meaning).

\subsection{Distinguishing Common and Unique Themes}

Following Hycner's recommended list of steps describing the phenomenological analysis of interview data, themes that are common to most or all the interviews were identified. Subsequently, themes that are unique to a single interview were also distinguished. Finally, general and unique themes were placed back into the overall context from which they emerged (Hycner, 1985). The resulted general and unique themes for the interviews are discussed on the next pages. They are also shown in Figure 2.

Table 2. Codes (Units of Relevant Meaning) \& the Developed Clusters (Themes)

\begin{tabular}{|c|c|c|}
\hline \multicolumn{2}{|l|}{ Units of Relevant Meaning (Codes) } & \multirow[t]{2}{*}{$\begin{array}{c}\text { Clusters of Units of Relevant Meaning } \\
\text { (Themes) }\end{array}$} \\
\hline $\begin{array}{l}\text { - "Automatic marking" } \\
\text { - "Easy grading" } \\
\text { - "Creating MCQ questions on papers needs more work" } \\
\text { - "Reusing is an advantage" } \\
\text { - "Collaborating and sharing resources" }\end{array}$ & 1) & \\
\hline $\begin{array}{l}\text { - "Quiz every session" } \\
\text { - "More quizzes prepares them slowly to achieve" } \\
\text { - "The use of computers made it possible" }\end{array}$ & 2) & $\begin{array}{l}\text { Increased rate of occurrence of } \\
\text { assessments }\end{array}$ \\
\hline $\begin{array}{l}\text { - "Marking essays can't be automatic" } \\
\text { - "Marking the essay questions is an issue" } \\
\text { - "Not easy" } \\
\text { - "Takes the same time" }\end{array}$ & 3) & Difficulty in marking essay questions \\
\hline $\begin{array}{l}\text { - "takes a long time to get used to the system" } \\
\text { - "not so easy at the beginning" } \\
\text { - "was not used to it" } \\
\text { - "Faced some technical problems" }\end{array}$ & 4) & Time consuming at the beginning \\
\hline $\begin{array}{l}\text { - "instant feedback" } \\
\text { - "Allows students to see their marks immediately after submission" } \\
\text { - "Students know where they stand" } \\
\text { - "they can get their results instantly" } \\
\text { - "get the marks very quickly" }\end{array}$ & 5) & $\begin{array}{l}\text { Increased opportunity for timely } \\
\text { feedback }\end{array}$ \\
\hline $\begin{array}{l}\text { - "Used assessments to control attendance" } \\
\text { - "Made them more participative" } \\
\text { - "Progress in the students' performance" } \\
\text { - "They are the digital generation. They can use these things easily" }\end{array}$ & 6) & Encourages student participation \\
\hline $\begin{array}{l}\text { - "Have to be very strong in using computers and sometimes in typing" } \\
\text { - "Some students still prefer paper-and-pencil test" } \\
\text { - "Resisted using it at the beginning" }\end{array}$ & 7) & Requires specific computer skills \\
\hline $\begin{array}{l}\text { - "they normally highlight what they believe is important" } \\
\text { - "some students feel that using keyboards is very noisy" } \\
\text { - "are used to writing notes and highlighting text" }\end{array}$ & 8) & Some students still prefer traditional tests \\
\hline $\begin{array}{l}\text { - "Randomizing questions" } \\
\text { - "Nice features like randomizing" } \\
\text { - "One Question at a time" } \\
\text { - "Showing the exam question by question" } \\
\text { - "Providing different sets of questions" }\end{array}$ & 9) & Helps to reduce cheating in assessments \\
\hline $\begin{array}{l}\text { - "students like it when they see their marks right away after submission } \\
\text { even if they get low marks" } \\
\text { - "Absorbs lots of students' shock in relation to the assessment" } \\
\text { - "Reducing the number of complaints" }\end{array}$ & 10) & $\begin{array}{l}\text { Minimizes student complaints about } \\
\text { marks }\end{array}$ \\
\hline $\begin{array}{l}\text { - "Problems with technology" } \\
\text { - "Lockdown browser may rise some technical issues" } \\
\text { - "Lockdown browser froze on students" }\end{array}$ & 11) & A possibility of facing technical issues \\
\hline
\end{tabular}


- "A need for physical separators to eliminate the cheating incidents"

- "There is a scope of cheating"

- "Tendency of looking at each other's work"

- "Taking pictures"

- "Archiving is easier to handle"

- "less steps are required to archive. It became faster"

- "a couple of clicks to get your files stored in a safe place"

- "Depends on how you set the system"

- "the test must be downloaded first"

- "There have been issues and we needed to call the educational technology specialist"
12) Requires using cheating prevention techniques

13) Students' work is archived securely

14) Teachers need good technical skills to manage course contents

\section{THE STUDY RESULTS}

As a result of following the steps in the data collection and explicitation process, the qualitatively different central themes below emerged:

1) Online CBA as a workload management tool

2) Online $\mathrm{CBA}$ as an instrument that enhances student satisfaction and attentiveness

3) Online CBA as a way to facilitate the management of assessments

4) Online CBA as an effective archiving system for assessments and Students' work

These central themes are described in more details below

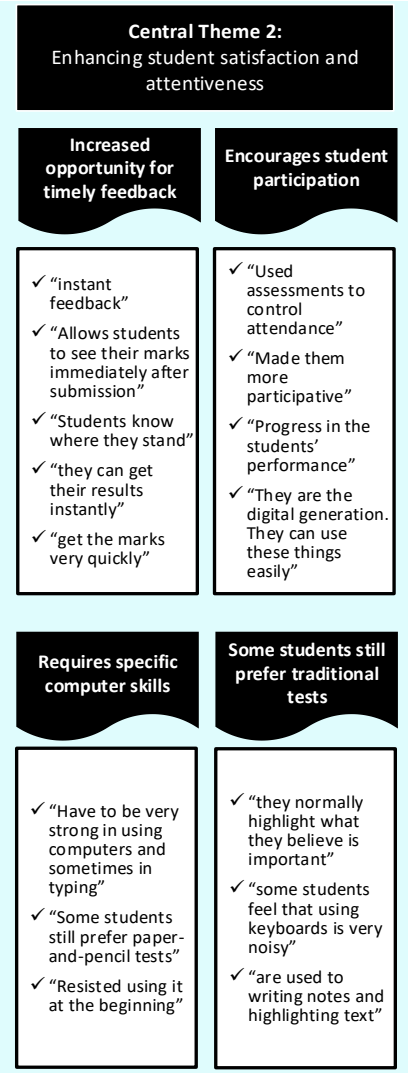
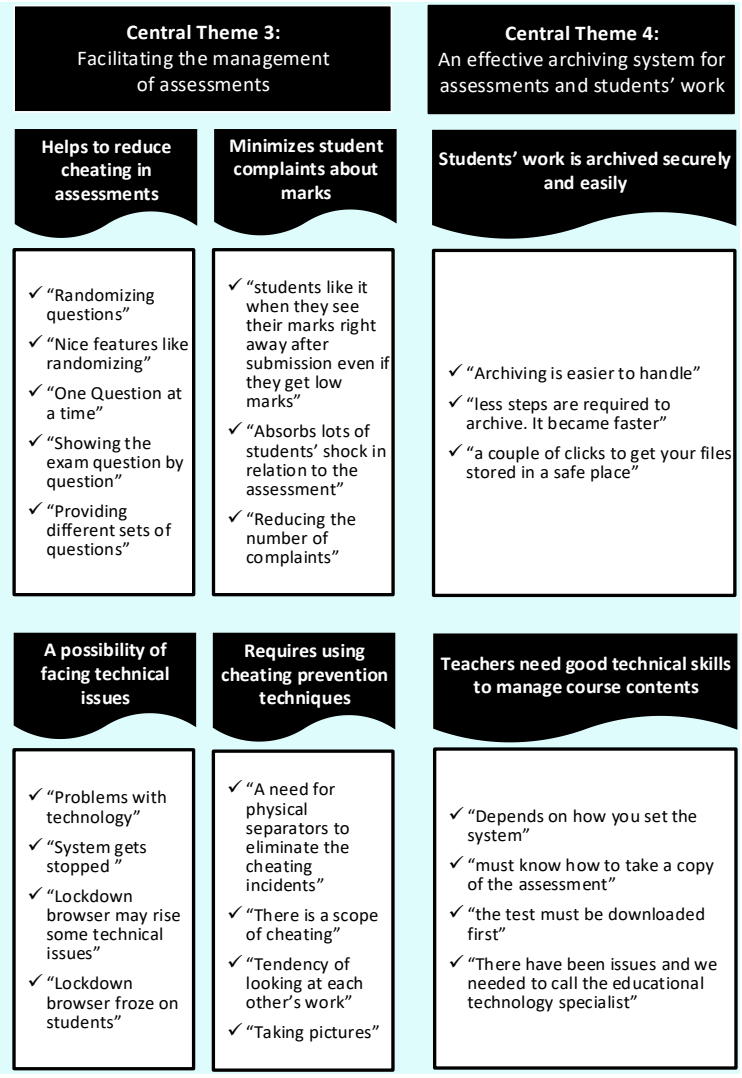

Figure 1. Central Themes, Themes, and Codes (Units of Relevant Meaning) 


\subsection{CBA as a Workload Management Tool}

The data collected during the interviews indicated that using online CBA helped teachers reduce the time needed for marking, allowing them to spend their time in dealing with other critical work. This permitted them to spend extra time in creating and putting into operation higher quality assessments, and recycle the core concepts through other activities. This was demonstrated by the following comments made by the interviewees:

$$
\text { “It saved a lot of my time."...(Interviewee-1) }
$$

“BB Learn gave me what I call easy grading. [...] I see it way easier”...( Interviewee-2)

“we can utilize our time in doing other things. ”...(Interviewee-3)

Additionally, some teachers believe that using online CBA allows them to increase the rate of occurrence of assessments. This was evident by the following comments made in the interviews.

"I am giving a quiz every session. More quizzes prepares them slowly to achieve”...(Interviewee-1)

$$
\text { “it made it possible to give more quizzes"...( Interviewee-2) }
$$

Although there seems to be concrete evidence that online CBA allows teachers to manage their marking load, the data gathered shows that teachers faced some difficulty in designing essay questions that can be marked automatically. As a result, some teachers had to mark some of the essay questions manually. This was evident by many comments such as the following:

"We tried to do that by providing the system with some acceptable phrases or sentences [...] I believe that marking essays can't be automatic. "...(Interviewee-1)

“There is always a possibility that the system marks it wrongly. I always double check the mark”...( Interviewee-3)

In addition, one interviewee stated that she had to invest a great amount of time at the beginning to get used to the new system. Following is one of the comments she made in the interview:

"Most of us needed training on how to write questions and use available functionalities"...(Interviewee-3)

\subsection{CBA as an Instrument that Enhances Student Satisfaction and Attentiveness}

This theme considers the likelihood of using online CBA as an instrument that encourages student satisfaction and attentiveness. The collected data indicates that online CBA increased the opportunity for timely and detailed feedback. This had a very positive effect on the students' satisfaction level as is clear in the following comments that are made by two of the interviewees:

"the feature that my students like the most is the instant feedback"...(Interviewee-1)

“It allows students to see their marks immediately after submission. They love that!”...( Interviewee-1)

"This helped them to get the mark very quickly. "...(Interviewee-3)

Interviewees also commented on how using CBA had encouraged students' participation. Two of the interviewees stated that they used computer-based assessments to control attendance by holding early morning assessments in class. This guaranteed that students came on time and participated for the rest of the class since they knew that they are likely to have another assessment at the beginning of the next class. This was evident by the following comments made in the interviews.

"In general, when students know they have a quiz at the beginning of the lesson, they make sure that they are in class on time. [...] this also made them more participative"... (Interviewee-1)

“Having these quizzes resulted in a good progress in the students' performance."... (Interviewee-2) 
Conversely, interviewees also believe that using online CBA will not be effective unless students already have acquired good technical skills. This was obvious in the following comments:

"Students have to be very strong in using computers and sometimes in typing. [...] was complaining that the time was not enough. The reason for is related to her typing speed. "...(Interviewee-1)

"Some students still prefer paper-based tests. They feel that it's not easy to use computers to provide their answers. [...] they resisted using it at the beginning. "...(Interviewee-2)

Furthermore, one interviewee indicated that some of her students still prefer pencil-and-paper assessments rather than computer-based assessments. She stated that these students felt more comfortable when taking the test on papers than on computers. They found it easier to read the text on papers, especially that they could highlight what they believe is important and add notes when needed. This was obvious in the comments of interviewee-2:

"Some of them may possibly feel happy with using pen and paper. [...]"...(Interviewee-2)

\subsection{Online CBA as a Way to Facilitate the Management of Assessments}

Some of the interviewees pointed out that online CBA facilitated the management of their assessments. They believe that using online CBA helped them to reduce cheating incidents. For instance, it enabled them to use a feature called 'random blocks' to help ensure that students see their own sets of questions. Random blocks select questions at random to be presented each time the test is taken. This was evident in the comments of two interviewees':

"Randomising questions was a good solution. It reduced the chances of cheating" ...(Interviewee-1)

“It is better to show them one question at a time. ....(Interviewee-3)

Additionally, the data collected shows that using computer-based assessments helped the interactive multimedia teachers minimise the number of students' complaints about their marks. Interviewee-3 gave the following comment:

"the most important thing for many of our students is their marks [...] As you know, the number of students visiting the faculty room increases in the exam period."...(Interviewee-3)

"students like it when they see their marks right away after submission even if they get low marks. This doesn't only please them. It also reduces the number of complaints. They trust that computers don't make mistakes." ...(Interviewee-3)

In contrast, the gathered data shows that all interviewees are concerned about the possibility that students might experience technical problem during the exam. One of the interviewees even believe that at least one computer support specialist must be present at all computer-based exams. Following are some of the comments made by the interviewees:

"Lockdown browser froze on students. I had to ask for help from both the Ed Tech and the TSD guys. I had to stop the exam [...]"...(Interviewee-1)

"Lockdown browser may rise some issues. ”...(Interviewee-3)

Besides, another interviewee stressed that there is a chance that students cheat in a CBA. She recommends the installation of physical separators between the computers units used for testing at the college. She believes that this helps eliminate the cheating incidents. Following is one of her comments related to this point:

"Some students have the tendency of looking at each other's work. [...] Not having these physical separators increases the chances of cheating. "...(Interviewee-1) 


\subsection{Online CBA as an Effective Archiving System for Assessments and Students' Work}

This theme reflects on the possibility of using online CBA as an effective archiving system. The data investigation shows that two of the interviewees saw online CBA as an effective archiving system where they can store both the assessments and samples of students' work in a secure place. This was evident in the following comments:

"I personally prefer dealing with softcopies rather than physical ones. Now, it doesn't take more than a couple of clicks to get your files from a safe place" ...(Interviewee-1)

“less steps are required to archive. It became faster” ...(Interviewee-2)

On the other hand, some interviewees also believe that using online CBA as an archiving system will not be effective unless teachers already have been trained on how to store their files on Bb Learn and have learned to take full advantage of the system. Interviewees have all stated that they have attended a number of training sessions to be able to use this feature effectively. This was evident in the comments of two interviewees':

"We needed some training on the system to know about how and where we can store these files. "...(Interviewee-1)

"it was difficult to start with. [...] There have been issues and we needed to call the educational technology specialist. " ...(Interviewee -3)

\section{COMMON AND UNIQUE THEMES}

In order to understand and explore the participants' awareness of the phenomenon under investigation and that is "Using CBA in teaching interactive multimedia classes", the researchers started by identifying the similarities and differences between the experiences of the teachers who participated in this research. They looked for the themes that were common for most or all of the interviews, and then the themes that were exclusive to a single interviewee were noted. The outcomes of this phase of the analysis are depicted in Figure 2 .

\subsection{Common Themes (All or Most of the Interviewees)}

Not all the emerged themes were common amongst all interviewees. The common themes amongst all interviewees were centered on the reduced marking load, the possibility of facing technical issues, and the need for teachers to have good technical skills to be able to manage course contents effectively. Additionally, Interviewee-1 and Interviewee-2 believed that using online CBAs allowed for an increased rate of occurrence of assessments. They also pointed out that this kind of automation of assessments encouraged student participation and attentiveness. Additionally, they both believe that using online CBAs requires students to have specific computer skills. They also claimed that using this tool allowed them to archive the assessments and students' work easily and securely.

Furthermore, Interviewee-1 and Interviewee-3 believed that using online CBA does not necessarily automate the marking of all types of questions. They declared that there is a difficulty in marking essay questions. They also pointed out that there is an increased opportunity for timely feedback. The last theme that was common between these two interviewees is that CBAs helped them reduce cheating in assessments. These themes (the ones shared between Interviewee-1 and Interviewee-2, and the ones shared between Interviewee-1 and Interviewee-3) are considered as common themes since the number of interviewees represents the majority that is two thirds of the sample. 


\subsection{Unique Themes (Individual Interviewees)}

The analysis of collected data shows that some of the emerged themes were discussed by one interviewee only. For example, the theme focusing on how some students still prefer traditional tests was expressed by interviewee- 2 only. Likewise, the themes related to minimizing students complaints about marks, the great amount of time required at the initial stage of using online CBAs, and the need for using cheating prevention techniques was only expressed by interviewee-3, and these themes are considered unique themes.

As argued by Tesch (1944), identifying the common themes is one way of recognizing the "invariants", the shared experiences that do not vary across the interviewees, and therefore, can be seen as the essence of the phenomenon or the phenomenon's constituents. However, the minority voices or unique themes cannot be neglected. They are as important as commonalities with regard to the phenomenon researched. These unique themes are seen as individual ways in which the phenomenon reveals itself. They can make us aware of the range of distinctiveness in the shared experience (Groenewald, 2004; Hycner, 1985; Tesch, 1944). Hence, both the common and the unique themes have been analyzed carefully.
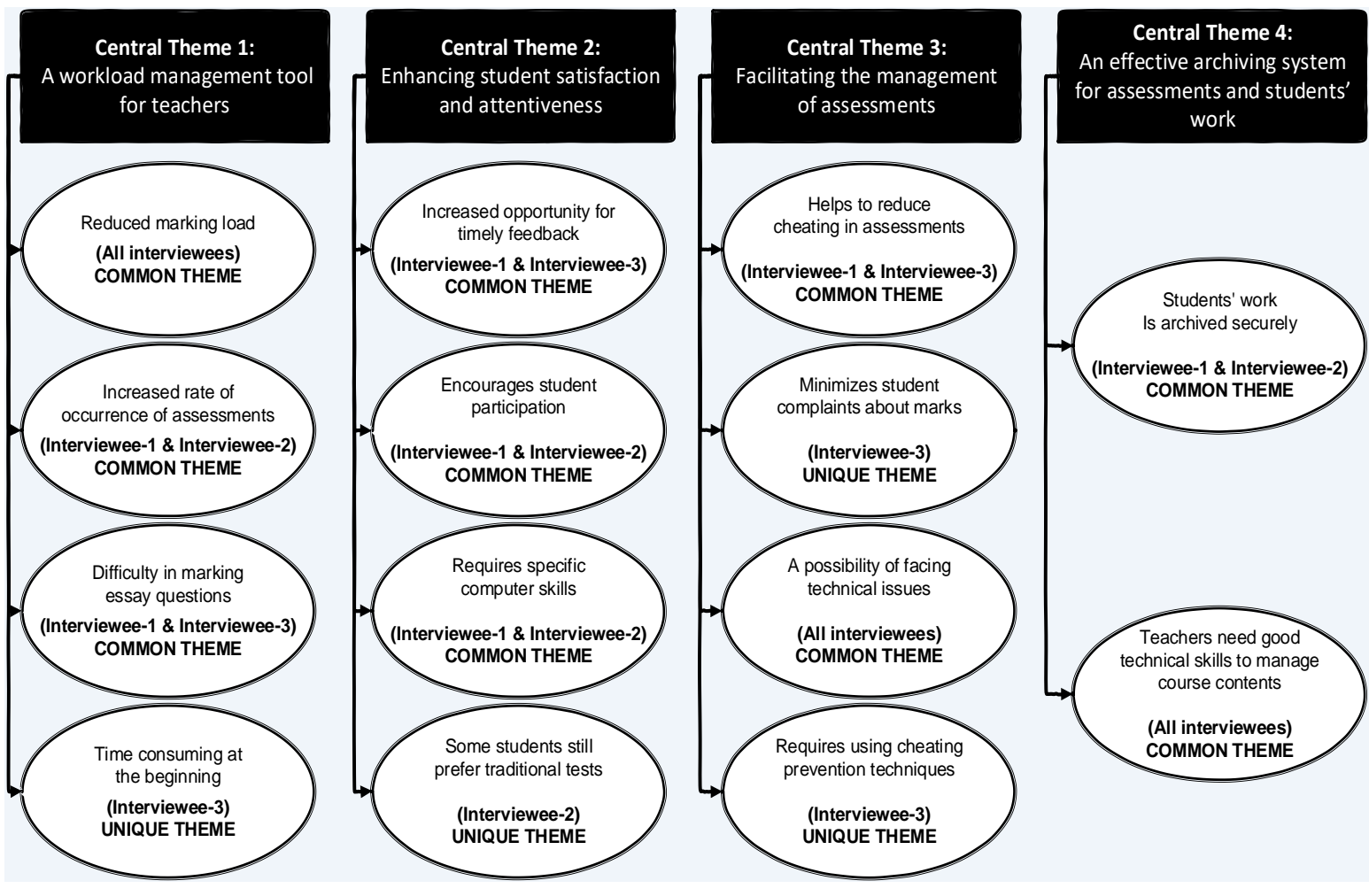

Figure 2. Common and Unique Themes

\section{DISCUSSION}

At the end of the study, the researchers rated their findings for a degree of match with the earlier specified expectations. Their findings are different from their expectations in that some expectations remained unconfirmed and some findings were not anticipated. For example, it became evident from the analysis of the emerged central themes that the use of online CBA is perceived as presenting both values and challenges. These are presented in Table- 3 below.

All interviewees were able to identify one value of using online CBA in their Interactive Multimedia classes. This value is the reduced marking load. This value is consistent with the findings of Peat (2002) and Ricketts and Wilks (2001) who listed the 'reduction of marking load for staff' as one of the main benefits of 
using computer-based assessments. They believe that the time taken for marking and giving back the results compromises the time that can be utilized for general help and guidance. Similarly, Terzis, Moridis, and Economides (2012) listed time reduction as one of the advantages of using CBA.

Other values of using online CBA mentioned by most of the interviewees were related to: first, the increased rate of occurrence of assessments; second, the increased opportunity for timely feedback; third, encouraging students' participation; fourth, reducing cheating in assessments; and fifth, the ability to archive assessments and student's work easily and securely. The first and third values are in harmony with the findings of Bull and McKenna (2004) who indicated that one of the reasons academics may wish to use CBA is to increase the frequency of assessments, thereby encouraging students to learn, participate, and practice skills. The second value is in line with the findings of many previous studies. For example, Thelwall (2000) asserted that "the most obvious way in which computerization of assessment can be a virtue is through instant marking and feedback". He believed that instant feedback is often more effective than when given after a delay; the fourth value is consistent with the recommendation of Csapó et al. (2012) who studied a range of security issues in Computer-Based Assessment. This is due to the fact that randomization of items may pose other justice problems which might disadvantage or advantage some students; and finally, the fifth value is in harmony with the findings of Amelung et al. (2011) who assured that storing assignments and students' work centrally is very helpful, especially if they can be accessed quickly and easily.

Table 3. Values and Challenges as Percieved by the Interviewees

\begin{tabular}{|c|c|c|c|c|c|}
\hline & & $\begin{array}{l}\text { A workload } \\
\text { management tool } \\
\text { for teachers }\end{array}$ & $\begin{array}{l}\text { Enhancing student } \\
\text { satisfaction and } \\
\text { attentiveness }\end{array}$ & $\begin{array}{l}\text { Facilitating the } \\
\text { management of } \\
\text { assessments }\end{array}$ & $\begin{array}{l}\text { An effective archiving } \\
\text { system for assessments } \\
\text { and students' work }\end{array}$ \\
\hline \multirow{3}{*}{ 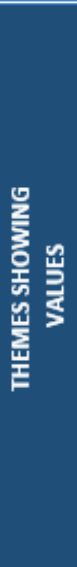 } & \multirow{2}{*}{ 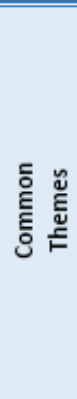 } & $\begin{array}{l}\text { Reduced marking } \\
\text { load } \\
\text { (All interviewees) }\end{array}$ & $\begin{array}{l}\text { Increased } \\
\text { opportunity for } \\
\text { timely feedback } \\
\text { Interviewee-1 } \\
\text { Interviewee-3 }\end{array}$ & \multirow[t]{2}{*}{$\begin{array}{l}\text { Helps to reduce } \\
\text { cheating in } \\
\text { assessments } \\
\text { Interviewee-1 } \\
\text { Interviewee-3 }\end{array}$} & \multirow[t]{2}{*}{$\begin{array}{l}\text { Students' work is archived } \\
\text { securely } \\
\text { Interviewee-1 } \\
\text { Interviewee-2 }\end{array}$} \\
\hline & & $\begin{array}{l}\text { Increased rate of } \\
\text { occurrence of } \\
\text { assessments } \\
\text { Interviewee-1 } \\
\text { Interviewee-2 }\end{array}$ & $\begin{array}{l}\text { Encourages student } \\
\text { participation } \\
\text { Interviewee-1 } \\
\text { Interviewee-2 }\end{array}$ & & \\
\hline & 壱 & & & $\begin{array}{l}\text { Minimises student } \\
\text { complaints about } \\
\text { marks } \\
\text { Interviewee-3 }\end{array}$ & \\
\hline \multirow{2}{*}{ 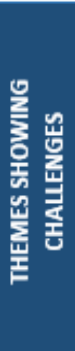 } & 总 & $\begin{array}{l}\text { Difficulty in } \\
\text { marking essay } \\
\text { questions } \\
\text { Interviewee-1 } \\
\text { Interviewee-3 }\end{array}$ & $\begin{array}{l}\text { Requires specific } \\
\text { computer skills } \\
\text { Interviewee-1 } \\
\text { Interviewee-2 }\end{array}$ & $\begin{array}{l}\text { A possibility of facing } \\
\text { technical issues } \\
\text { (All interviewees) }\end{array}$ & $\begin{array}{l}\text { Teachers need good } \\
\text { technical skills to manage } \\
\text { course contents } \\
\text { (All interviewees) }\end{array}$ \\
\hline & 竎 & $\begin{array}{l}\text { Time consuming at } \\
\text { the beginning } \\
\text { Interviewee-3 }\end{array}$ & $\begin{array}{l}\text { Some students still } \\
\text { prefer traditional } \\
\text { tests } \\
\text { Interviewee-2 }\end{array}$ & $\begin{array}{l}\text { Requires using } \\
\text { cheating prevention } \\
\text { techniques } \\
\text { Interviewee-3 }\end{array}$ & \\
\hline
\end{tabular}

The value that was mentioned by only one interviewee was minimizing students' complaints about marks. This is seen as an obvious result of the immediate presentation of different types of feedback that provides students with an analysis and explanation of their marks.

Like any other educational technology, there are yet challenges to be addressed when it comes to the use of online CBA. The first challenge that all interviewees considered was the possibility of facing technical issues. Concerns about technical issues or discomfort with computer technology are acknowledged in the existing international literature. The second challenge is the need for teachers to have good technical skills to 
manage the course contents. That is, they have to know not only how to create and manage assessments, but also how to store assessments and related files and, ultimately, to organize the contents. Participants showed that a training session on how to manage the course contents is highly needed to be able to get the best out of using CBAs.

Other challenges of using online CBA mentioned by most of the interviewees were related to: first, the difficulty teachers may encounter in marking essay questions. Participants believe that writing essay questions may require providing many criteria per question, and even this does not guarantee a good level of automation. They stated that they always depend on manual grading; and second, the need for specific computer skills. Some studies have revealed that for a successful implementation of CBA, students require some degree of computer literacy (Alderson, 2000). Difficulties for students lacking computer skills and other technical issues are acknowledged in the existing international literature.

On the other hand, the time required in the initial stage of implementation, the preference of using traditional tests, and the need to use cheating prevention techniques were conceived as unique challenges. The reason why they are considered unique is that they have been mentioned by one interviewee only. The first challenge can be possibly alleviated by enrolling teachers in extensive BB Learn training courses upon starting the use of CBA; whereas the second challenge can be addressed by providing students with some help about using CBA in the classroom before introducing computer-based assessments. The researched finds the third challenge logical. It can be addressed by designing at least one assessment lab that has these physical separators installed. This lab can be used by different assessments related to different courses.

\section{LIMITATIONS AND CONCLUSION}

In this section, it is important to admit that the time constraint of this study has restricted the amount of data that could be collected and analyzed. This is seen as a limitation of this study as it constrained the researchers to conduct only three interviews, the minimum number recommended by Giorgi (2009), who stated that in phenomenological method in human science, it is recommended that one uses at least three participants. While the collected data were adequate to enable a phenomenological exploration of the range of experiences expressed by the teachers, having more time would allow for conducting more interviews, and therefore, provide sufficient opportunities for the full range of experiences communicated by the Interactive Multimedia teachers. Additionally, the applicability of the results of this study to a general population is questionable as the researchers explored the experiences of only teachers using CBA when teaching an interactive multimedia course.

To conclude, as shown in Table 3, the investigation of data has shown that the implementation of online CBA is perceived by the interviewees as presenting both values and challenges. This conclusion is not only based on the themes that are common to most or all of the interviewees. It is also based on the individual variations or unique themes since they are as important as commonalities with regard to the phenomenon researched (Groenewald, 2004). Additionally, this study has confirmed that some changes were seen in the students' day-to-day practices. For instance, the use of CBA has enhanced their satisfaction and attentiveness, and encouraged them to participate more.

On the other hand, as it is common with other research studies, this research has uncovered new research questions like: How do students feel about the use of online CBA? What factors affect male and female students' perceptions towards the use of CBA? Why there might be common or unique themes amongst the interviewees? In addition, how this particular implementation of CBA can be enhanced?

\section{REFERENCES}

Alderson, J. C. 2000. Technology in testing: The present and the future. System, 28, 593-603.

Amelung, M., Krieger, K. \& Rosner, D. 2011. E-Assessment as a Service. Learning Technologies, IEEE Transactions on, 4, 162-174.

Bull, J. \& Mckenna, C. 2004. Blueprint for Computer-assisted Assessment, Psychology Press.

Clariana, R. \& Wallace, P. 2002. Paper-based versus computer-based assessment: key factors associated with the test mode effect. British Journal of Educational Technology, 33, 593-602. 
Creswell, J. W. 2012. Educational Research: Planning, Conducting, and Evaluating Quantitative and Qualitative Research, Boston, MA, London, Pearson.

Csapó, B., Ainley, J., Bennett, R., Latour, T. \& Law, N. 2012. Technological Issues for Computer-Based Assessment. In: Griffin, P., Mcgaw, B. \& Care, E. (eds.) Assessment and Teaching of 21st Century Skills. Springer Netherlands.

Deutsch, T., Herrmann, K., Frese, T. \& Sandholzer, H. 2012. Implementing computer-based assessment - A web-based mock examination changes attitudes. Computers \& Education, 58, 1068-1075.

Gearing, R. E. 2004. Bracketing in Research: A Typology. Qualitative Health Research, 14, 1429-1452.

Giorgi, A. 2009. The descriptive phenomenological method in psychology; a modified Husserlian approach. Reference and Research Book News, 24.

Groenewald, T. 2004. A phenomenological research design illustrated. International Journal of Qualitative Methods, 3 , Article 4

Husserl, E. 1931. Ideas: general introduction to pure phenomenology, London : New York, London : Allen \& Unwin New York : Humanities Press.

Hycner, R. H. 1985. Some guidelines for the phenomenological analysis of interview data. Human Studies, 8, $279-303$.

Larsson, J. \& Holmström, I. 2007. Phenomenographic or phenomenological analysis: does it matter? Examples from a study on anaesthesiologists' work. International Journal of Qualitative Studies on Health \& Well-Being, 2, 55-64.

Marton, F. \& Booth, S. 1997. Learning and Awareness, New yourk, Routledge.

Maypole, J. \& Davies, T. G. 2001. Students' Perceptions of Constructivist Learning in a Community College American History 11 Survey Course. Community College Review, 29, 54-79.

Moustaka, C. 1994. Phenomenological research methods. Phenomenological research methods. SAGE Publications, Inc, Thousand Oaks, CA, SAGE Publications, Inc.

Patton, M. 2002. Qualitative Research \& Evaluation Methods, Thousand Oaks, CA, Sage Publications:.

Peat, M. \& Franklin, S. 2002. Supporting student learning: the use of computer-based formative assessment modules. British Journal of Educational Technology, 33, 515-523.

Prosser, M., Trigwell, K. \& Taylor, P. 1994. A phenomenographic study of academics' conceptions of science learning and teaching. Learning and Instruction, 4, 217-231.

Ricketts, C. \& Wilks, S. 2002. Improving student performance through computer-based assessment: Insights from recent research. Assessment \& evaluation in higher education, 27, 475-479.

Terzis, V., Moridis, C. N. \& Economides, A. A. 2012. How student's personality traits affect Computer Based Assessment Acceptance: Integrating BFI with CBAAM. Computers in Human Behavior, 28, 1985-1996.

Tesch, R. 1944. Emerging themes: The researcher's experience. Phenomenology+ Pedagogy, 5, 230-241.

Thelwall, M. 2000. Computer-based assessment: a versatile educational tool. Computers \& Education, 34, 37-49.

Tufford, L. \& Newman, P. 2012. Bracketing in Qualitative Research. Qualitative Social Work, 11, $80-96$. 